\title{
Dual Pathway Inhibition for Vascular Protection in Patients with Atherosclerotic Disease: Rationale and Review of the Evidence
}

\author{
${ }^{1}$ Thrombosis and Atherosclerosis Research Institute and McMaster \\ University, Hamilton, Ontario, Canada \\ ${ }^{2}$ Division of Cardiology, University of Florida College of Medicine, \\ Jacksonville, Florida, United States \\ 3 Department of Cardiology and Angiology, University Hospital \\ Tübingen, Tübingen, Germany \\ ${ }^{4}$ Research and Development Pharmaceuticals, Bayer AG, Wuppertal, \\ Germany
}

Jeffrey Ian Weitz ${ }^{1}$ Dominick J. Angiolillo ${ }^{2}$ Tobias Geisler ${ }^{3}$ Stefan Heitmeier ${ }^{4}$

Thromb Haemost 2020;120:1147-1158.

\begin{abstract}
Address for correspondence Jeffrey lan Weitz, MD FRCP(C), FACP, FRSC, Thrombosis and Atherosclerosis Research Institute and McMaster University, 237 Barton St. E., Hamilton, Ontario L8L $2 \times 2$, Canada (e-mail: weitzj@taari.ca).
\end{abstract}

\author{
Abstract \\ Keywords \\ - coronary artery \\ disease \\ - dual pathway \\ inhibition \\ - nonvitamin $\mathrm{K}$ \\ antagonist oral \\ anticoagulants \\ - peripheral artery \\ disease \\ - rivaroxaban
}

Despite advances in secondary prevention strategies in patients with cardiovascular disease, the residual risk of recurrent atherothrombotic events remains high. Dualantiplatelet therapy is the standard of care for secondary prevention in patients with acute coronary syndrome (ACS), whereas single antiplatelet therapy, generally with aspirin, is the standard of care for secondary prevention in stable patients with coronary artery disease (CAD), peripheral artery disease (PAD), or cerebrovascular disease. However, atherosclerotic plaque disruption not only triggers platelet activation but also results in thrombin generation because of tissue factor exposure. Therefore, blocking both pathways by combining antiplatelet therapy with an anticoagulant, or dual pathway inhibition (DPI), has the potential to be more effective than inhibiting either pathway alone. The benefit of DPI has been demonstrated in the ATLAS ACS 2TIMI 51, COMPASS, and VOYAGER PAD trials, where the combination of rivaroxaban vascular dose $(2.5 \mathrm{mg}$ twice daily) plus aspirin significantly reduced the risk of atherothrombotic events compared with aspirin across a broad range of patients, including those with recent ACS, those with chronic CAD and/or PAD, and patients with $P A D$ who have undergone peripheral revascularization. This article provides the rationale for this regimen in more detail, including why the DPI regimen with the rivaroxaban vascular dose was developed for vascular protection in a broad spectrum of patients with atherosclerotic disease.

\section{Introduction}

Atherosclerosis is a systemic disease that can affect the coronary, cerebral, or peripheral arteries. ${ }^{1}$ Atherosclerotic plaques usually appear early in life, but only become symptomatic when there is vascular occlusion by expanding plaques or when unstable plaques rupture and there is superimposed thrombosis. ${ }^{2,3}$ Clinically, atherosclerosis manifests as cardiovascular disease (CVD), which is the leading cause of mortality and morbidity worldwide, and includes coronary artery disease (CAD), peripheral artery disease (PAD), and cerebrovascular disease (CeVD). ${ }^{2,4-7}$ Many patients with atherosclerosis have received

October 30, 2019

accepted

May 8, 2020 (c) 2020 Georg Thieme Verlag KG Stuttgart · New York
DOI https://doi.org/ $10.1055 / \mathrm{s}-0040-1713376$. ISSN 0340-6245. 
A

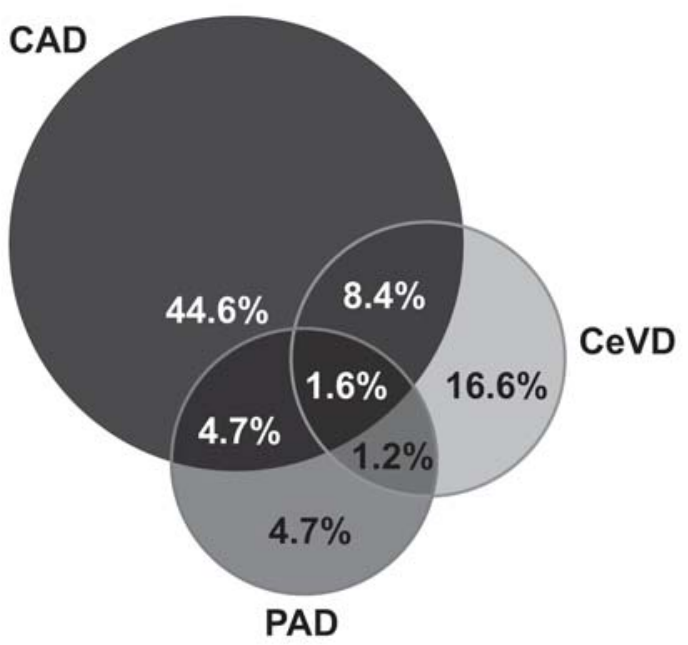

B

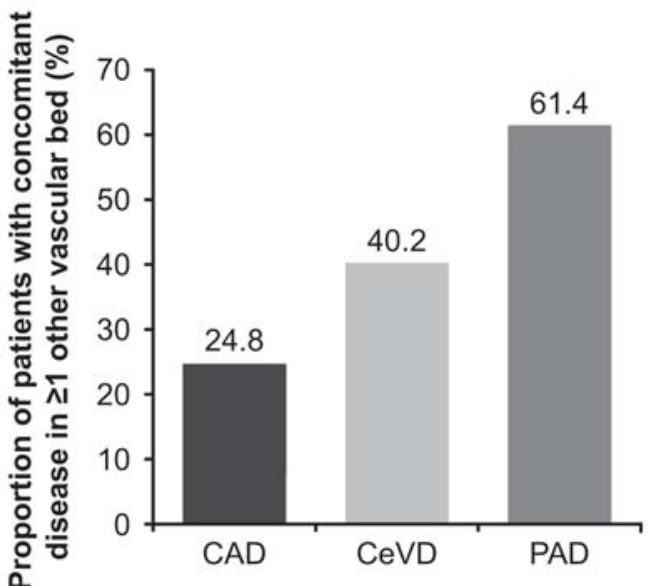

Fig. 1 Prevalence of polyvascular disease in the REACH registry. ${ }^{8}$ (A) Proportion of patients of the total REACH population $(N=67,888)$ with polyvascular disease. (B) Proportion of patients with coronary artery disease (CAD), cerebrovascular disease (CeVD), and peripheral artery disease (PAD) who have concomitant disease in $\geq 1$ other vascular bed.

polyvascular involvement, with symptoms occurring in more than one vascular bed. ${ }^{8}$ In the global Reduction of Atherothrombosis for Continued Health (REACH) registry, $15.9 \%$ of patients with symptomatic atherothrombotic disease had polyvascular involvement; $8.4 \%$ of these patients had CAD and CeVD, 4.7\% had CAD and PAD, 1.2\% had CeVD and PAD, and 1.6\% had CAD, CeVD, and PAD (-Fig. 1). ${ }^{8}$ The risk of fatal and nonfatal adverse cardiovascular (CV) events increased as a function of the number of symptomatic disease locations, ${ }^{9,10}$ emphasizing the importance of secondary CV prevention, particularly in patients with polyvascular disease. ${ }^{1,11}$

Antiplatelet therapy has been the mainstay of CV prevention in patients with CVD. ${ }^{12-16}$ The focus on antiplatelet strategies reflects the fact that arterial thrombi, which form under high shear conditions, are rich in platelets and contain less fibrin than venous thrombi, which form where blood flow is sluggish. ${ }^{17}$ Single or dual-antiplatelet therapy (DAPT) is used to reduce the risk of atherothrombotic events in patients with CVD. Single antiplatelet therapy usually involves the administration of aspirin or clopidogrel, whereas DAPT combines aspirin with a $\mathrm{P}_{2} \mathrm{Y}_{12}$ inhibitor, such as clopidogrel, ticagrelor, or prasugrel. ${ }^{12-16}$ DAPT is the standard of care (SOC) for secondary prevention in patients with acute coronary syndrome (ACS), ${ }^{12-15,18}$ whereas single antiplatelet therapy is recommended for patients with symptomatic PAD or chronic CAD. ${ }^{11,16,19}$ The recently published European Society of Cardiology guidelines on chronic coronary syndromes (CCS) now recommend the addition of a second antithrombotic drug to aspirin for long-term secondary prevention in patients with a high risk of ischemic events and without a high risk of bleeding. ${ }^{20}$ Despite improvements in SOC and guideline recommendations for secondary prevention in patients with $C A D$ and $P A D$, the residual risk of $C V$ events remains high in such patients, ranging from approximately 15 to $30 \%$ at 3 years. ${ }^{21,22}$ Therefore, more effective antithrombotic strategies are needed.
Atherothrombotic events are caused by disruption or erosion of atherosclerotic plaques and superimposed thrombosis. ${ }^{23,24}$ Plaque disruption results in thrombus formation via the concomitant activation of platelets and coagulation. ${ }^{17,23}$ Consequently, antithrombotic strategies that only focus on platelet inhibition may not fully suppress recurrent atherothrombotic events. This observation prompted the investigation of dual pathway inhibition (DPI) strategies, where an antiplatelet agent such as aspirin is combined with an anticoagulant.

The first phase 3 trial to investigate the efficacy and safety of DPI in patients with CVD was the Anti-Xa Therapy to Lower cardiovascular events in Addition to aspirin with/without thienopyridine therapy in Subjects with Acute Coronary Syndrome (ATLAS ACS 2-TIMI 51) trial. This trial demonstrated that the addition of rivaroxaban ( 2.5 or $5 \mathrm{mg}$ twice daily) to a background of single antiplatelet therapy (low-dose aspirin) or DAPT (aspirin plus a P2Y $\mathrm{Y}_{12}$ inhibitor) reduced atherothrombotic risk in patients with a recent ACS compared with antiplatelet therapy alone. Although DPI was associated with an increased risk of major bleeding and intracranial hemorrhage (ICH), there was no increase in the risk of fatal bleeding. ${ }^{25}$ This led to the regulatory approval of DPI in this setting in some countries. ${ }^{26-28}$

More recently, the Cardiovascular OutcoMes for People Using Anticoagulation StrategieS (COMPASS) trial showed that this benefit of DPI extended into patients with chronic CAD or PAD. The combination of rivaroxaban $2.5 \mathrm{mg}$ twice daily plus aspirin, but not rivaroxaban $5 \mathrm{mg}$ twice daily alone, was shown to be more effective than aspirin alone in reducing the risk of major adverse CV events (MACE) in patients with chronic CAD or PAD. Combination therapy was again associated with an increased risk of major bleeding, but there was no significant increase in the risk of fatal bleeding or ICH. ${ }^{29-31}$ These results led to the widespread approval of rivaroxaban $2.5 \mathrm{mg}$ twice daily plus aspirin for patients with chronic CAD or PAD. ${ }^{26-28}$ 
Finally, the recent Vascular Outcomes Study of ASA (acetylsalicylic acid) Along with Rivaroxaban in Endovascular or Surgical Limb Revascularization for Peripheral Artery Disease (VOYAGER PAD) trial extended the evidence base for DPI to include patients with symptomatic PAD undergoing lower extremity revascularization. Patients treated with rivaroxaban $2.5 \mathrm{mg}$ twice daily plus aspirin had a $15 \%$ reduction in the risk of the composite outcome of myocardial infarction (MI), ischemic stroke, CV death, acute limb ischemia (ALI), and major amputation of vascular etiology. ${ }^{32}$ The risk of the primary safety outcome of Thrombolysis In Myocardial Infarction (TIMI) major bleeding was not significantly different with DPI versus aspirin in the VOYAGER PAD study. ${ }^{32}$

Although the results of these trials highlight the value of DPI in a broad range of patients, the rationale for DPI needs to be fully understood by physicians in order to optimize the benefits of this treatment. After reviewing the results of the ATLAS ACS 2-TIMI 51, COMPASS, and VOYAGER PAD trials in more detail, this article addresses four commonly asked questions about DPI with rivaroxaban $2.5 \mathrm{mg}$ twice daily plus aspirin:

1. What is the rationale for combining an antiplatelet agent with an anticoagulant?

2. Why should a lower dose of rivaroxaban be used rather than the higher dose that is used for stroke prevention in patients with atrial fibrillation (AF) or for venous thromboembolism (VTE) treatment?

3. Why should twice-daily dosing with rivaroxaban $2.5 \mathrm{mg}$ be used rather than once-daily dosing?

4. Which patients might benefit most from the dual pathway regimen?

\section{Evidence Base for Dual Pathway Inhibition in Patients with Cardiovascular Disease}

The phase 3 ATLAS ACS 2-TIMI 51 trial showed that adjunctive therapy with rivaroxaban (2.5 or $5 \mathrm{mg}$ twice daily) on a background of antiplatelet therapy significantly reduced the primary efficacy endpoint, defined as a composite of $\mathrm{CV}$ death, MI, or stroke, in more than 15,000 patients with a recent ACS, compared with placebo (8.9\% vs. $10.7 \%$, hazard ratio [HR], 0.84; $95 \%$ confidence interval $[\mathrm{CI}], 0.74-0.96$; $p=0.008$ ). This benefit with rivaroxaban was consistent among subgroups except for patients with a history of stroke or transient ischemic attack (HR, 1.57; 95\% CI, 0.75-3.31). ${ }^{25}$

More recently, the phase 3 COMPASS trial showed that the benefit of DPI extended to patients with chronic CAD or PAD. Thus, DPI with rivaroxaban $2.5 \mathrm{mg}$ twice daily plus aspirin, but not monotherapy with rivaroxaban $5 \mathrm{mg}$ twice daily alone, was superior to aspirin alone for the prevention of MACE, defined as the composite of CV death, MI, or stroke, in a population of 27,395 patients with chronic CAD or PAD. ${ }^{29}$ MACE occurred in $4.1 \%$ of patients receiving rivaroxaban $2.5 \mathrm{mg}$ twice daily plus aspirin, in $5.4 \%$ of those receiving aspirin alone, and in $4.9 \%$ of those receiving rivaroxaban alone (rivaroxaban plus aspirin vs. aspirin alone: absolute risk reduction, 1.3\%; number needed to treat, 77; HR, 0.76; $95 \% \mathrm{CI}, 0.66-0.86 ; p<0.001$; rivaroxaban alone vs. aspirin alone: absolute risk reduction, $0.5 \%$; number needed to treat, 200; HR, 0.90; 95\% CI, 0.79-1.03; $p=0.12) .{ }^{29}$ Compared with aspirin alone, the combination of rivaroxaban $2.5 \mathrm{mg}$ twice daily plus aspirin also reduced the risk of stroke by $42 \%$ (HR, $0.58 ; 95 \% \mathrm{CI}, 0.44-0.76 ; p<0.0001) .^{33}$ The decreased risk of stroke was primarily driven by a reduction in the risk of ischemic stroke (HR, 0.51; 95\% CI, 0.38-0.68; $p<0.0001$ ) with relative risk reductions of 70 and $60 \%$ for cardioembolic stroke and embolic stroke of undetermined source, respectively. ${ }^{33,34}$ Rivaroxaban $2.5 \mathrm{mg}$ twice daily in combination with aspirin was also shown to reduce MACE and major adverse limb events compared with aspirin or rivaroxaban alone in patients with PAD, including those with carotid artery disease (defined as previous carotid artery revascularization or asymptomatic carotid artery stenosis of at least $50 \%) .{ }^{31}$ Thus, a reduction in the risk of MACE and major adverse limb events was achieved with the combination of rivaroxaban vascular dose and aspirin, but not with low-dose rivaroxaban alone. ${ }^{29}$

Building on the evidence for the utility of DPI with rivaroxaban $2.5 \mathrm{mg}$ twice daily plus aspirin are the recent results from the phase 3 VOYAGER PAD trial, which investigated this treatment strategy in patients with symptomatic PAD undergoing lower extremity revascularization. Compared with aspirin alone, rivaroxaban $2.5 \mathrm{mg}$ twice daily plus aspirin significantly reduced the 3-year incidence of the composite of MI, ischemic stroke, CV death, ALI, and major amputation for vascular causes compared with aspirin (17.3\% with DPI vs. $19.9 \%$ with aspirin, $\mathrm{HR}, 0.85 ; 95 \% \mathrm{CI}$, $0.76-0.96 ; p=0.009$ ). This broad benefit was seen early, with separation of the Kaplan-Meier curves at 3 months, which was maintained over time and was consistent across major subgroups. In addition, the incidence of the secondary outcome of unplanned index limb revascularization for recurrent ischemia was significantly lower with rivaroxaban $2.5 \mathrm{mg}$ twice daily plus aspirin compared with aspirin alone (HR, 0.88; 95\% CI, 0.79-0.99; $p=0.03$ ), while death from any cause did not differ between treatment groups (HR, 1.08; 95\% CI, 0.92-1.27; $p=0.34$ ). ${ }^{32}$ Overall, these findings complement the results of the ATLAS ACS 2-TIMI 51 and COMPASS trials and provide further support for the use of DPI with rivaroxaban $2.5 \mathrm{mg}$ twice daily plus aspirin in patients with CVD.

As expected when an anticoagulant is added to an antiplatelet agent, the risk of major bleeding was increased with rivaroxaban plus aspirin compared with aspirin alone in both the ATLAS ACS 2-TIMI 51 and COMPASS trials, although there was no increase in the risk of fatal bleeding. ${ }^{25,29}$ In the ATLAS ACS 2-TIMI 51 trial, the rate of TIMI major bleeding, not related to coronary artery bypass grafting, was higher in patients receiving rivaroxaban 2.5 or $5 \mathrm{mg}$ twice daily compared with placebo $(2.1 \%$ vs. $0.6 \%, \mathrm{HR}, 3.96 ; 95 \% \mathrm{CI}$, 2.46-6.38; $p<0.001$ ). Rates of TIMI minor bleeding and ICH were also increased with rivaroxaban compared with placebo ( $1.3 \%$ vs. $0.5 \%, p=0.003$ and $0.6 \%$ vs. $0.2 \%, p=0.009$, respectively), but the rate of fatal bleeding did not significantly differ between the treatment groups $(0.3 \%$ vs. $0.2 \%$, $p=0.66) .{ }^{25}$ Furthermore, the rates of major bleeding were 
lower with rivaroxaban $2.5 \mathrm{mg}$ twice daily than with the $5 \mathrm{mg}$ twice daily dose ( $1.8 \%$ and $2.4 \%$, respectively). ${ }^{25}$

Results from the COMPASS trial reported major bleeding in $3.1 \%$ of patients receiving rivaroxaban $2.5 \mathrm{mg}$ twice daily plus aspirin versus $1.9 \%$ of patients receiving aspirin alone (absolute risk increase, 1.2\%; number needed to harm, 83; HR, 1.70; 95\% CI, 1.40-2.05; $p<0.001){ }^{29}$ The rates of fatal bleeding were 0.2 and $0.1 \%$ with DPI and aspirin alone, respectively (HR, 1.49; 95\% $\mathrm{CI}, 0.67-3.33 ; p=0.32$ ), whereas the rates of ICH were $0.2 \%$ in both groups (HR, $1.10 ; 95 \% \mathrm{CI}$, $0.59-2.04 ; p=0.77) .{ }^{29}$ Therefore, even though combination therapy resulted in an increased risk of major bleeding, the risk of fatal or critical organ bleeding (including ICH) was not increased compared with aspirin alone. ${ }^{31}$ In addition, the risk of the composite net clinical benefit outcome of $\mathrm{CV}$ death, stroke, MI, fatal bleeding, or symptomatic bleeding into a critical organ was found to be lower with rivaroxaban $2.5 \mathrm{mg}$ twice daily plus aspirin compared with aspirin alone (HR, 0.80; 95\% CI, 0.70-0.91; $p<0.001$ ), indicating an improved benefit-risk profile for the combination therapy compared with aspirin alone. ${ }^{29}$

In the VOYAGER PAD trial, the 3-year rate of TIMI major bleeding in patients treated with rivaroxaban $2.5 \mathrm{mg}$ twice daily plus aspirin was not significantly different compared with patients receiving aspirin alone $(2.65 \%$ vs. $1.87 \%, \mathrm{HR}, 1.43$; $95 \% \mathrm{CI}, 0.97-2.10 ; p=0.07)$. However, using the International Society on Thrombosis and Haemostasis criteria, the rate of major bleeding was significantly higher in patients treated with rivaroxaban $2.5 \mathrm{mg}$ twice daily plus aspirin compared with aspirin alone (5.94\% vs. 4.06\%, HR, 1.42; 95\% CI, 1.10-1.84; $p=0.007)$. There was no excess in ICH with rivaroxaban $2.5 \mathrm{mg}$ twice daily plus aspirin compared with aspirin alone $(0.60 \% \mathrm{vs}$. $0.90 \%, \mathrm{HR}, 0.78 ; 95 \% \mathrm{CI}, 0.38-1.61)$, and the rate of fatal bleeding was $0.21 \%$ in both groups. ${ }^{32}$

\section{What Is the Rationale for Combining an Antiplatelet Agent with an Anticoagulant?}

The progression from early atherosclerotic lesions to ruptureprone plaques involves complex interplay between coagulation and inflammation pathways. ${ }^{3,24,35,36}$ Rupture of atherosclerotic plaques induces simultaneous activation of platelets and of the coagulation cascade (-Fig. 2), resulting in the formation of superimposed thrombi, which are mainly composed of platelets. ${ }^{17}$ Platelets adhere to collagen and von Willebrand factor (vWF) exposed at sites of plaque rupture. ${ }^{17}$ Adherent platelets become activated and release adenosine diphosphate and thromboxane $\mathrm{A}_{2}$, platelet agonists that activate ambient platelets, thereby recruiting them to the site of injury. Platelet activation leads to the activation of glycoprotein (GP) IIb/IIIa on the surface of platelets. ${ }^{17}$ Binding of fibrinogen to activated GPIIb/IIIa on adjacent platelets bridges them together, which leads to platelet aggregation. Under high shear conditions, unfolded vWF can also contribute to this bridging process. ${ }^{17}$ Concomitant with platelet activation and aggregation, plaque rupture exposes tissue factor, which initiates the coagulation cascade and triggers thrombin generation and fibrin formation. Fibrin monomers polymerize into strands that tie the platelet aggregates together and stabilize the platelet-rich thrombus. ${ }^{36}$

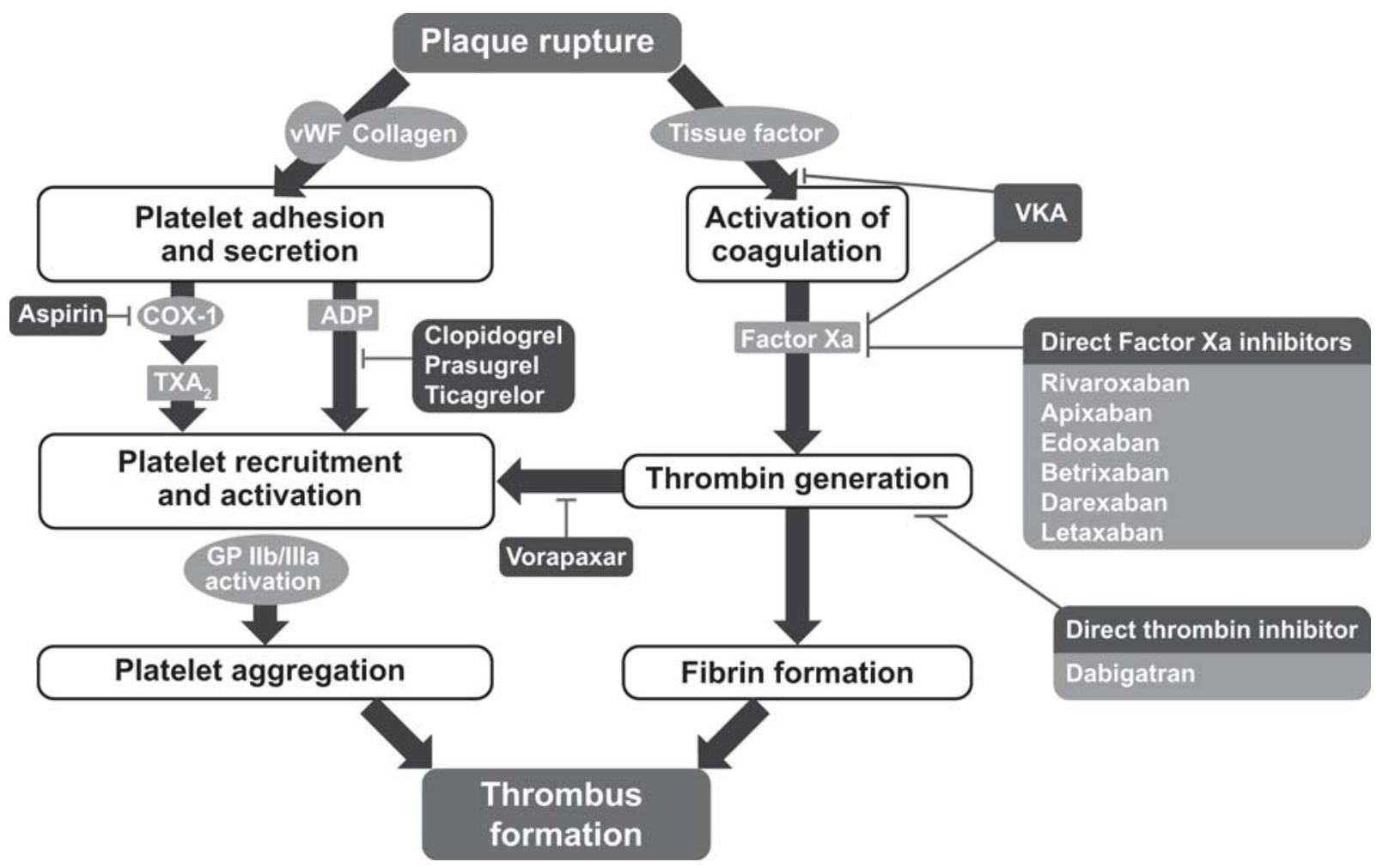

Fig. 2 Pathways for thrombus formation and targets for oral antithrombotic agents. The dual pathway of thrombus formation comprises platelet activation/aggregation and coagulation. Antiplatelet agents and anticoagulants target the respective pathways at different sites. ADP, adenosine diphosphate; COX, cyclooxygenase; GP, glycoprotein; TXA 2 , thromboxane $A_{2}$; VKA, vitamin K antagonist; vWF, von Willebrand factor. 
The coagulation and platelet pathways intersect at several sites (-Fig. 2). For example, thrombin is not only an important mediator of the coagulation cascade but also acts as a potent platelet agonist that induces platelet activation and aggregation via activation of protease-activated receptors (PARs) PAR-1 and PAR-4 on the platelet surface. ${ }^{17,37}$ Recent data suggest that factor $\mathrm{Xa}$, which converts prothrombin to thrombin, may also activate PAR-1. ${ }^{37-39}$ In turn, platelets play an important part in amplifying thrombin generation, because the intrinsic tenase and prothrombinase complexes, which mediate the generation of factor Xa and thrombin, respectively, assemble on the activated platelet surface. ${ }^{17,37}$

Because of the coordinated, synergistic involvement of platelets and coagulation in atherothrombosis, treatment strategies targeting both fibrin generation and platelet activation, termed "DPI", are likely to be more effective than those inhibiting only one of these two pathways. This concept is supported by the observations that: (1) despite SOC therapy, markers of coagulation system activation (e.g., fibrinopeptide A, prothrombin fragment F1.2, and D-dimer), and thrombin generation remain elevated for months after $\mathrm{ACS}^{40-42}$; (2) preclinical studies show that combining an anticoagulant with single antiplatelet therapy or DAPT provides additive or synergistic effects in in vitro assays and enhances antithrombotic efficacy in animal models ${ }^{43,44}$; and (3) low doses of rivaroxaban reduce thrombin generation in patients on antiplatelet therapy. ${ }^{45}$

As mentioned above, antiplatelet therapy is the SOC for secondary prevention of CV events in patients with CVD. However, despite improvements in secondary prevention strategies, such as DAPT, the risk of CV events remains high. Trials comparing DAPT consisting of aspirin plus a $\mathrm{P}_{2} \mathrm{Y}_{12}$ inhibitor (e.g., clopidogrel or ticagrelor) with aspirin alone revealed that more intensified platelet inhibition resulted in a greater reduction in atherothrombotic risk but also increased the risk of major bleeding. ${ }^{46-48}$ For example, in the CHARISMA trial, which compared clopidogrel plus aspirin with aspirin alone in patients with documented atherosclerotic disease or multiple atherothrombotic risk factors, there was no significant difference in the rate of CV events with DAPT, but DAPT was associated with an increased risk of bleeding. ${ }^{46}$ In the subgroup of patients with documented prior MI, stroke, or symptomatic PAD, the DAPT regimen had a significant benefit, but it increased the risk of moderate, although not severe, bleeding. ${ }^{47}$ In the PEGASUS-TIMI 54 trial, ticagrelor plus aspirin was associated with a significant reduction in the risk of MACE and an increased risk of major bleeding in patients with a history of MI 1 to 3 years previously. ${ }^{49}$ Finally, the EUCLID trial revealed no benefit of the more potent P2Y $\mathrm{Y}_{12}$ antagonist ticagrelor over clopidogrel for secondary prevention in patients with symptomatic PAD, although the risk of major bleeding was similar between treatment groups. ${ }^{50}$

Vorapaxar, a PAR-1 antagonist that targets a different pathway of platelet activation than aspirin or the $\mathrm{P}_{2} \mathrm{Y}_{12}$ inhibitors, has also been evaluated for secondary prevention in patients with CVD. ${ }^{51-53}$ When added on top of SOC in patients with ACS, ${ }^{53}$ or those with a history of MI, ischemic stroke, or PAD, ${ }^{51,52}$ vorapaxar reduced the incidence of CV events versus placebo, but was associated with an increased risk of serious bleeding events. ${ }^{51-53}$ Thus, the limited success of intensified antiplatelet regimens suggested that another strategy was needed to reduce the residual atherothrombotic risk in patients with chronic CAD or PAD.

A new and more effective approach may be to target thrombin generation in addition to platelet activation. Thus, such a DPI regimen would combine an antiplatelet agent, such as aspirin, with an oral anticoagulant (OAC) that targets fibrin formation, such as a vitamin $\mathrm{K}$ antagonist (VKA) (-Fig. 2; - Table 1). This concept was confirmed in phase 3 trials such as Antithrombotics in the Secondary Prevention of Events in Coronary Thrombosis-2 (ASPECT-2) ${ }^{54}$ and Warfarin-Aspirin Reinfarction Study II (WARIS II), ${ }^{55}$ which assessed the efficacy and safety of aspirin, a VKA, or a combination of both in patients with recent ACS. When the VKA was dosed to produce a therapeutic international normalized ratio of 2 to 3, VKA alone or combined with aspirin was shown to be more effective in reducing the risk of $\mathrm{CV}$ events than antiplatelet therapy with aspirin alone in patients with ACS, but also resulted in an increased risk of bleeding. ${ }^{54,55}$ Attempts to reduce the risk of bleeding by lowering the intensity of VKA therapy (target international normalized ratio of 1.5-2.5) were unsuccessful, because the efficacy in decreasing atherothrombotic events and all-cause mortality was also reduced. ${ }^{56}$ Another disadvantage of VKAs is that their use is inconvenient, because of the large within- and between-patient variability in dose response, thus requiring frequent coagulation monitoring and dose adjustment, as well as careful avoidance of potential food-drug and drug-drug interactions. ${ }^{57,58}$

Non-VKAOACs (NOACs) attenuate thrombin generation and fibrin production by inhibiting factor Xa or thrombin, and therefore also have the potential to be used as part of a DPI strategy in combination with an antiplatelet agent ( - Fig. 2). As mentioned above, it has also been suggested that concomitant administration of NOACs and antiplatelet agents synergistically enhances the antithrombotic effect. ${ }^{59-61}$ In contrast to VKAs, NOACs do not require routine monitoring, have fewer drugdrug interactions, and are unaffected by changes in dietary intake of vitamin K. ${ }^{27,58,62,63}$ In addition, NOACs have been shown to have an improved benefit-risk profile compared with VKAs, such as warfarin, in patients with AF or VTE. ${ }^{64,65}$

Clinical trials have been conducted to assess the efficacy and safety of NOACs in combination with aspirin in patients with acute or chronic CVD as part of a DPI regimen (-Table 1) ${ }^{66}$ In the phase 2 RandomizEd Dabigatran Etexilate Dose Finding Study in Patients With Acute Coronary Syndromes Post Index Event With Additional Risk Factors for Cardiovascular Complications Also Receiving Aspirin and Clopidogrel: Multi-centre, Prospective, Placebo Controlled, Cohort Dose Escalation Study (RE-DEEM) trial, dabigatran (110-150 mg twice daily) added to DAPT significantly reduced coagulation activity in patients with a recent MI, but was associated with a dose-dependent increase in bleeding events. ${ }^{67}$ In the phase 3 APixaban for Prevention of Acute Ischemic Events 2 (APPRAISE-2) trial, apixaban (5 mg twice daily) was compared with placebo on top of background therapy that included aspirin with or without a P2Y $_{12}$ receptor antagonist. The trial was terminated early, because 
Table 1 Trials investigating combination therapies of antiplatelet and oral anticoagulant agents in patients with CAD and PAD

\begin{tabular}{|c|c|c|c|c|}
\hline Drug class & Trial & Patient population & Treatment arms & Key outcomes \\
\hline \multicolumn{5}{|c|}{ Post-ACS setting } \\
\hline \multirow[t]{2}{*}{$\begin{array}{l}\text { VKA plus } \\
\text { antiplatelet }\end{array}$} & ASPECT-2 $2^{54}$ & $\begin{array}{l}\text { Patients with acute } \mathrm{Ml} \text { or } \\
\text { unstable angina }(N=999)\end{array}$ & $\begin{array}{l}\text { Coumadin plus aspirin } \\
\text { vs. aspirin alone } \\
\text { vs. coumadin alone }\end{array}$ & $\begin{array}{l}\text { - Coumadin combined with aspirin } \\
\text { or given alone was superior to aspirin alone } \\
\text { in reducing CV events and death but was } \\
\text { associated with a higher risk of bleeding }\end{array}$ \\
\hline & WARIS $I^{55}$ & $\begin{array}{l}\text { Patients with acute } \mathrm{Ml} \\
(N=3,630)\end{array}$ & $\begin{array}{l}\text { Warfarin plus aspirin } \\
\text { vs. aspirin alone } \\
\text { vs. warfarin alone }\end{array}$ & $\begin{array}{l}\text { - Warfarin combined with aspirin } \\
\text { or given alone was more effective than } \\
\text { aspirin alone in reducing the incidence of } \\
\text { CV events but was associated with a higher } \\
\text { risk of bleeding }\end{array}$ \\
\hline \multirow[t]{5}{*}{$\begin{array}{l}\text { NOAC plus } \\
\text { antiplatelet }\end{array}$} & RE-DEEM ${ }^{67}$ & $\begin{array}{l}\text { Patients with recent NSTEMI } \\
\text { or STEMI }(N=1,861)\end{array}$ & $\begin{array}{l}\text { Dabigatran } 50 \mathrm{mg}, 75 \mathrm{mg}, 110 \mathrm{mg} \text {, } \\
\text { or } 150 \mathrm{mg} \text { bid plus DAPT } \\
\text { vs. placebo plus DAPT }\end{array}$ & $\begin{array}{l}\text { - Dabigatran added to DAPT resulted in a } \\
\text { dose-dependent increase in bleeding } \\
\text { events and significantly reduced } \\
\text { coagulation activity in patients with } \\
\text { a recent MI }\end{array}$ \\
\hline & APPRAISE-2 ${ }^{66}$ & $\begin{array}{l}\text { Patients with recent unstable } \\
\text { angina, NSTEMI, or STEMI } \\
(N=7,392)\end{array}$ & $\begin{array}{l}\text { Apixaban } 5 \mathrm{mg} \text { bid plus standard } \\
\text { antiplatelet therapy } \\
\text { vs. placebo plus standard antiplatelet } \\
\text { therapy }\end{array}$ & $\begin{array}{l}\text { - Apixaban added to standard antiplatelet } \\
\text { therapy increased the risk of major bleed- } \\
\text { ing without a significant reduction in re- } \\
\text { current ischemic events (trial was } \\
\text { terminated prematurely) }\end{array}$ \\
\hline & $\begin{array}{l}\text { ATLAS ACS } \\
\text { TIMI } 46^{69}\end{array}$ & $\begin{array}{l}\text { Patients with recent unstable } \\
\text { angina, NSTEMI, or STEMI } \\
\text { ( } N=3,491 \text { patients) }\end{array}$ & $\begin{array}{l}\text { Rivaroxaban } 5 \mathrm{mg}, 10 \mathrm{mg}, 15 \mathrm{mg} \text {, or } \\
20 \mathrm{mg} \text { bid plus standard antiplatelet } \\
\text { therapy } \\
\text { vs. placebo plus standard antiplatelet } \\
\text { therapy }\end{array}$ & $\begin{array}{l}\text { - Rivaroxaban added to standard antiplatelet } \\
\text { therapy resulted in a dose-dependent in- } \\
\text { crease in bleeding events and a reduction in } \\
\text { ischemic events, even with the lowest dose }\end{array}$ \\
\hline & $\begin{array}{l}\text { ATLAS ACS } \\
2 \text {-TIMI } 51^{25}\end{array}$ & $\begin{array}{l}\text { Patients with recent unstable } \\
\text { angina, NSTEMI, or STEMI } \\
\text { ( } N=15,526 \text { patients) }\end{array}$ & $\begin{array}{l}\text { Rivaroxaban } 2.5 \mathrm{mg} \text { bid plus standard } \\
\text { antiplatelet therapy } \\
\text { vs. rivaroxaban } 5 \mathrm{mg} \text { bid plus standard } \\
\text { antiplatelet therapy } \\
\text { vs. placebo plus standard antiplatelet } \\
\text { therapy }\end{array}$ & $\begin{array}{l}\text { - Both doses of rivaroxaban reduced the risk } \\
\text { of the composite end point of } \mathrm{CV} \text { death, MI, } \\
\text { or stroke, with an increase in major bleed- } \\
\text { ing and ICH but not fatal bleeding } \\
\text { - The } 2.5 \mathrm{mg} \text { bid dose was associated with } \\
\text { fewer fatal bleeding events than the } 5 \mathrm{mg} \\
\text { bid dose }\end{array}$ \\
\hline & GEMINI ACS $1^{71}$ & $\begin{array}{l}\text { Patients with unstable } \\
\text { angina, NSTEMI or STEMI } \\
(N=3,037)\end{array}$ & $\begin{array}{l}\text { Rivaroxaban } 2.5 \mathrm{mg} \text { bid plus } \mathrm{P}_{2} \mathrm{Y}_{12} \\
\text { inhibitor } \\
\text { vs. aspirin plus } \mathrm{P}_{2} \mathrm{Y}_{12} \text { inhibitor }\end{array}$ & 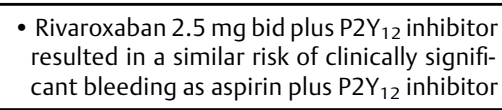 \\
\hline \multicolumn{5}{|c|}{ Chronic CAD and/or PAD } \\
\hline $\begin{array}{l}\text { NOAC plus } \\
\text { antiplatelet }\end{array}$ & COMPASS $^{29}$ & $\begin{array}{l}\text { Patients with chronic CAD } \\
\text { and PAD }(N=27,395)\end{array}$ & $\begin{array}{l}\text { Rivaroxaban } 2.5 \mathrm{mg} \text { bid plus aspirin vs. } \\
\text { rivaroxaban } 5 \mathrm{mg} \text { bid vs. aspirin }\end{array}$ & $\begin{array}{l}\text { - Rivaroxaban } 2.5 \mathrm{mg} \text { bid plus aspirin signif- } \\
\text { icantly reduced the risk of CV events com- } \\
\text { pared with aspirin or rivaroxaban alone and } \\
\text { increased the risk of major bleeding; how- } \\
\text { ever, fatal bleeding or ICH were not sig- } \\
\text { nificantly increased }\end{array}$ \\
\hline \multicolumn{5}{|c|}{ Symptomatic PAD following peripheral revascularization } \\
\hline $\begin{array}{l}\text { NOAC plus } \\
\text { antiplatelet }\end{array}$ & $\begin{array}{l}\text { VOYAGER } \\
\text { PAD }^{32,93}\end{array}$ & $\begin{array}{l}\text { Patients with symptomatic } \\
\text { PAD and recent lower } \\
\text { extremity revascularization }\end{array}$ & $\begin{array}{l}\text { Rivaroxaban } 2.5 \mathrm{mg} \text { bid plus aspirin vs. } \\
\text { aspirin }\end{array}$ & $\begin{array}{l}\text { - Rivaroxaban } 2.5 \mathrm{mg} \text { bid plus aspirin signif- } \\
\text { icantly reduced the risk of major adverse } \\
\text { cardiovascular and ischemic limb events } \\
\text { and did not significantly increase the risk of } \\
\text { TIMI major bleeding versus aspirin }\end{array}$ \\
\hline
\end{tabular}

Abbreviations: ACS, acute coronary syndrome; bid, twice daily; CAD, coronary artery disease; CV, cardiovascular; DAPT, dual-antiplatelet therapy; $\mathrm{ICH}$, intracranial hemorrhage; MI, myocardial infarction; NOAC, nonvitamin K antagonist oral anticoagulant; NSTEMI, non-ST segment elevation myocardial infarction; PAD, peripheral artery disease; STEMI, ST segment elevation myocardial infarction; TIMI, Thrombolysis In Myocardial Infarction; VKA, vitamin $\mathrm{K}$ antagonist.

apixaban (5 mg twice daily) did not significantly reduce the risk of ischemic events in patients with recent ACS, but led to an increase in major bleeding, including fatal bleeding and ICH. ${ }^{66}$ This full-dose apixaban regimen, which is similar to the one used as sole therapy for stroke prevention in the majority of patients with $\mathrm{AF},{ }^{66,68}$ was chosen based on phase 2 data from APPRAISE suggesting that apixaban doses of $2.5 \mathrm{mg}$ twice daily or $10 \mathrm{mg}$ once daily might have a favorable benefit-risk profile.

In the case of rivaroxaban, it was the lower-dose regimens that offered the best balance between efficacy and safety in the phase 2 ATLAS ACS-TIMI 46 trial. This trial investigated total daily doses of rivaroxaban ranging from 5 to $20 \mathrm{mg}$ administered once daily or twice daily in patients with recent ACS who were also receiving aspirin (75-100 mg once daily) with or without a thienopyridine. ${ }^{69}$ The risk of bleeding increased with higher doses of rivaroxaban, but lower doses were sufficient to reduce the risk of ischemic events. ${ }^{69}$ The two doses of rivaroxaban ( 2.5 and $5 \mathrm{mg}$ twice daily) identified in the ATLAS ACSTIMI 46 trial were assessed for reducing the risk of CV events in patients with recent ACS in the phase 3 ATLAS ACS 2-TIMI 51 trial. ${ }^{25}$ The combination of rivaroxaban $2.5 \mathrm{mg}$ twice daily or 
rivaroxaban $5 \mathrm{mg}$ twice daily with background therapy that included DAPT with aspirin and a thienopyridine (predominantly clopidogrel) significantly reduced the risk of MACE. ${ }^{25}$ Although the risks of major bleeding and ICH were increased, there was no difference in the risk of fatal bleeding compared with background therapy. ${ }^{25}$ While the $5 \mathrm{mg}$ twice daily dose was associated with a reduction in all-cause mortality, the lower $2.5 \mathrm{mg}$ twice daily dose was associated with a decrease in both CV and all-cause mortality. The reason why CV mortality was reduced in the rivaroxaban $2.5 \mathrm{mg}$ twice daily group but not in the $5 \mathrm{mg}$ twice daily group is unclear, but it could reflect the higher rate of bleeding with the $5 \mathrm{mg}$ twice daily dose. ${ }^{25}$ In a subanalysis of the ATLAS ACS 2-TIMI 51 trial in stented patients with ACS treated with DAPT, rivaroxaban $2.5 \mathrm{mg}$ twice daily also resulted in a reduction in stent thrombosis and mortality. ${ }^{70}$ These results confirmed that DPI with a low dose of a NOAC and DAPT improves protection against CV events in patients with ACS who have elevated biomarkers. In addition, the Study to Compare the Safety of Rivaroxaban Versus Acetylsalicylic Acid in Addition to Either Clopidogrel or Ticagrelor Therapy in Participants With Acute Coronary Syndrome 1 (GEMINI ACS 1) trial demonstrated a similar risk of clinically significant bleeding with rivaroxaban $2.5 \mathrm{mg}$ twice daily combined with a $\mathrm{P} \mathrm{Y}_{12}$ inhibitor compared with aspirin and a P2Y ${ }_{12}$ inhibitor for the treatment of patients with ACS, ${ }^{71}$ further supporting the rationale for using this DPI regimen after ACS.

\section{Why Should a Lower Dose of Rivaroxaban Be Used Rather than the Higher Dose that is Used for Stroke Prevention in Patients with Atrial Fibrillation or for Venous Thromboembolism Treatment?}

Rivaroxaban can be part of the treatment strategy to prevent ischemic events in patients with AF, VTE, and CVD, but the indications and dose recommendations differ among these patient populations (-Table 2) ${ }^{27,29,72}$ The doses recom- mended to reduce the risk of stroke in patients with $\mathrm{AF}$ and the risk of VTE are higher than that recommended for reducing the residual risk of CV events in patients with CVD who are concomitantly receiving antiplatelet therapy. ${ }^{27,29,72}$ The different indications and dose recommendations can be explained by the different pathophysiology and therapeutic goals of the various conditions. Thrombi formed under lowshear stress conditions, as in venous thrombosis and in the low-flow environment of the left atrial appendage in $\mathrm{AF}$, predominantly consist of fibrin, ${ }^{17,73}$ justifying the use of anticoagulants for the prevention of cardioembolic stroke and for the prevention and treatment of VTE. In contrast, in atherothrombosis, the thrombi that form under high-shear conditions are platelet-rich but thrombin-driven, thus indicating the need for an anticoagulant in addition to antiplatelet treatments in patients with CVD. ${ }^{17,23,74}$ Given the increased risk of bleeding when combining anticoagulant and antiplatelet therapies, it is essential to use the lowest effective dose of anticoagulant to minimize the risk of bleeding. Phase 2 and 3 trials showed that low-dose rivaroxaban combined with aspirin was effective in reducing $\mathrm{CV}$ events in patients with recent ACS and elevated biomarkers, with a satisfactory safety profile. ${ }^{25,27,69}$ The rivaroxaban doses of 2.5 and $5 \mathrm{mg}$ twice daily had the best balance between safety and efficacy in patients with recent ACS, and were therefore assessed in patients with stable CVD in the phase 3 COMPASS trial. ${ }^{25,29,69}$

\section{Why Should Twice-Daily Dosing with Rivaroxaban 2.5 mg Be Used Rather than Once-Daily Dosing?}

Rivaroxaban is absorbed rapidly, with maximum plasma concentrations achieved 2 to 4 hours after oral administration and peak factor Xa inhibition occurring after approximately 3 hours. ${ }^{75-77}$ Plasma concentrations of rivaroxaban increase in a dose-dependent manner and are closely correlated with the level of factor Xa inhibition, as well as prolongation of prothrombin time and activated partial thromboplastin

Table 2 Dose recommendations for rivaroxaban for different indications

\begin{tabular}{|c|c|}
\hline Indication $^{\mathrm{a}}$ & Treatment regimens/dose recommendations \\
\hline $\begin{array}{l}\text { Prevention of atherothrombotic events in adult } \\
\text { patients with } C A D \text { or } P A D^{26,27}\end{array}$ & Rivaroxaban $2.5 \mathrm{mg}$ bid coadministered with aspirin \\
\hline $\begin{array}{l}\text { Prevention of atherothrombotic events in adult } \\
\text { patients after an ACS event with elevated biomarkers }\end{array}$ & $\begin{array}{l}\text { Rivaroxaban } 2.5 \mathrm{mg} \text { bid coadministered with aspirin alone } \\
\text { or with aspirin plus clopidogrel or ticlopidine }\end{array}$ \\
\hline $\begin{array}{l}\text { Prevention of stroke and systemic embolism in } \\
\text { adult patients with nonvalvular } A F^{26,27}\end{array}$ & Rivaroxaban $20 \mathrm{mg}$ od ${ }^{\mathrm{b}}$ \\
\hline $\begin{array}{l}\text { Prevention of VTE in adult patients undergoing } \\
\text { elective hip or knee replacement surgery }{ }^{26,27}\end{array}$ & Rivaroxaban $10 \mathrm{mg}$ od \\
\hline $\begin{array}{l}\text { Treatment of DVT and PE, and prevention of } \\
\text { recurrent DVT and PE in adults } 56,27\end{array}$ & $\begin{array}{l}\text { Rivaroxaban } 15 \mathrm{mg} \text { bid Day } 1-21 \\
\text { Rivaroxaban } 20 \mathrm{mg} \text { bid Day } 22 \text { onwards } \\
\text { Rivaroxaban } 10 \mathrm{mg} \text { od or } 20 \mathrm{mg} \text { od following completion of at } \\
\text { least } 6 \mathrm{mo} \text { therapy for DVT or PE }\end{array}$ \\
\hline
\end{tabular}

Abbreviations: ACS, acute coronary syndrome; AF, atrial fibrillation; bid, twice daily; CAD, coronary artery disease; CV, cardiovascular; DVT, deep vein thrombosis; od, once daily; PAD, peripheral artery disease; PE, pulmonary embolism; VTE, venous thromboembolism.

aplease refer to label for exact wording.

bivaroxaban $15 \mathrm{mg}$ od is recommended in patients with creatinine clearance $\leq 50 \mathrm{~mL} / \mathrm{min}$. 
time. $^{76,78}$ The half-life of rivaroxaban is dose-dependent, as demonstrated in two phase 1 studies that compared the pharmacokinetics of 2.5 to $20 \mathrm{mg}$ doses of rivaroxaban in healthy male subjects. ${ }^{79}$ Whereas doses of $2.5 \mathrm{mg}$ are eliminated from the plasma with a half-life of approximately 5 hours, the half-life of 10 or $20 \mathrm{mg}$ doses is about twice as long. ${ }^{79}$ Therefore, because of the 5-hour half-life of the rivaroxaban $2.5 \mathrm{mg}$ dose, plasma levels at trough would be too low if that dose was administered once daily, which would compromise efficacy. Thus, a twice daily dosing regimen ensures that effective plasma levels are maintained throughout the day when rivaroxaban vascular doses are administered.

The longer half-life of rivaroxaban doses of $10 \mathrm{mg}$ and above provides a rationale for the once daily treatment regimens used for patients with AF and for VTE treatment $(20 \mathrm{mg})$, and for VTE prevention $(10 \mathrm{mg}) .{ }^{27}$ The high-dose once daily regimen for patients with AF and VTE is based on phase $2 \mathrm{~b}$ trials, in which once daily and twice daily dosing regimens had similar efficacy and safety profiles. ${ }^{80-82}$ To minimize the risk of bleeding, the lowest effective dose was assessed further in phase 3 clinical trials and ultimately approved for use in the respective indications. In patients with CVD, total daily rivaroxaban doses of 5 or $10 \mathrm{mg}$ were associated with less bleeding and similar efficacy compared with higher doses, as demonstrated in the phase 2 ATLAS ACS-TIMI 46 trial. $^{69}$ Based on the pharmacokinetic and pharmacodynamic profiles that suggest insufficient trough levels for once daily doses of rivaroxaban below $10 \mathrm{mg}$, a twice daily dosing regimen was selected. ${ }^{69,76}$ Rivaroxaban $5 \mathrm{mg}$ once daily is, therefore, not therapeutically equivalent to rivaroxaban $2.5 \mathrm{mg}$ twice daily in patients with chronic CAD or PAD. To maintain a clinically effective concentration of rivaroxaban throughout the day, which is required for continuous protection against atherothrombotic events, it is important to use a twice daily regimen for these patients.

\section{Which Patients Might Benefit Most from the Dual Pathway Regimen?}

Results from three phase 3 trials (ATLAS ACS 2-TIMI 51, COMPASS, and VOYAGER PAD), which included almost 50,000 patients in total, have established the utility of the DPI regimen in a broad range of patients, with subgroup analyses demonstrating consistent efficacy and safety results across major subgroups. ${ }^{25,29-32}$ However, patient subgroups at the highest absolute risk were shown to experience the greatest absolute benefit with DPI therapy. A risk-stratification analysis of the COMPASS trial population demonstrated that patients with the highest baseline risk, including those with polyvascular disease, renal impairment (estimated glomerular filtration rate [eGFR] $<60 \mathrm{~mL} / \mathrm{min}$ ), and those with a history of heart failure or diabetes, particularly benefited from the COMPASS regimen, as reflected by their higher absolute risk reductions. ${ }^{83}$

Consistent with the COMPASS trial and the risk-stratification analysis, the 2019 European Society of Cardiology guidelines on CCS now recommend considering adding a second antithrombotic agent to aspirin for long-term secondary prevention in patients with a low bleeding risk who are at high risk of ischemic events (i.e., those with diffuse multivessel CAD with at least one additional risk factor, such as diabetes that requires medication, recurrent MI, PAD, or chronic kidney disease with eGFR $15-59 \mathrm{~mL} / \mathrm{min}){ }^{20}$ This recommendation may also be considered for moderate-risk patients (i.e., those with multivessel/diffuse CAD and/or at least one other risk factor listed above, or heart failure) ${ }^{20}$ Antithrombotic agents that can be added to aspirin include the $\mathrm{P}_{2} \mathrm{Y}_{12}$ inhibitors clopidogrel, prasugrel or ticagrelor, and rivaroxaban, which is the only anticoagulant recommended for long-term secondary prevention in patients with CCS. ${ }^{20}$

The results of the COMPASS trial indicate that DPI improves CV outcomes and overall mortality in a broad patient population. The guidelines recommend considering DPI in patients $>1$ year post-MI or with multivessel CAD, whereas DAPT is primarily recommended for up to 1 year post-MI, although it may be continued longer in patients at low risk for bleeding and high risk for recurrent ischemic events. ${ }^{20}$ As expected with intensified antithrombotic therapies, both strategies-DPI and DAPTare associated with an increased risk of bleeding, which is acknowledged in the new guidelines. Therefore, a second antithrombotic agent is only recommended in patients who are not at high risk of bleeding (defined as a history of ICH; ischemic stroke or other intracranial pathology; recent gastrointestinal [GI] bleeding; anemia due to possible GI blood loss or other GI pathology associated with increased bleeding risk; liver failure; bleeding diathesis or coagulopathy; extreme old age or frailty; or renal failure requiring dialysis or eGFR $<15 \mathrm{~mL} / \mathrm{min} /$ $\left.\mathrm{m}^{2}\right) .{ }^{20}$ A recent review proposed a practical algorithm for selecting an antithrombotic strategy in patients with CCS. ${ }^{84}$

There are no head-to-head comparisons between DAPT and DPI in patients with CVD. Therefore, the choice of treatment needs to be individualized, based on balancing of the risks of ischemic events and bleeding. An analysis of data from the REACH registry showed that, while the risk of ischemic events increases with accumulating risk factors, the risk of serious bleeding increases at a much lower rate in a COMPASS-eligible population. ${ }^{85}$ Thus, patients with high ischemic risk appear to have a more favorable benefit-risk profile than those with a lower ischemic risk, suggesting that these patients may be good candidates for DPI.

Recently published treatment strategies suggest the use of DPI in patients with chronic vascular disease and additional high-risk factors, ${ }^{86-88}$ and in patients with symptomatic PAD. ${ }^{89}$ However, it is important to keep in mind that the management of patients with chronic CVD not only includes antithrombotic therapy but also lifestyle modifications and pharmacological interventions targeting other aspects of CV risk such as dyslipidemia, diabetes, and hypertension. ${ }^{20}$ The patients enrolled in the COMPASS trial were already receiving a high level of SOC, suggesting that DPI is beneficial even in well-managed patients.

\section{Conclusion and Future Directions}

DPI aims to reduce the risk of residual CV events by targeting both of the pathways involved in atherothrombosis: platelet aggregation and fibrin formation. In the ATLAS ACS 2-TIMI 
51, COMPASS, and VOYAGER PAD trials, a combination of rivaroxaban vascular dose ( $2.5 \mathrm{mg}$ twice daily) plus aspirin significantly reduced the risk of atherothrombotic events compared with aspirin in patients with ACS, chronic CAD, or $P A D$, including those with carotid artery disease, and in patients with symptomatic PAD undergoing lower extremity revascularization. The efficacy of rivaroxaban vascular dose as part of the COMPASS regimen in patients with chronic CAD and $\mathrm{PAD}$, in contrast to the high doses required for secondary $\mathrm{CV}$ prevention in patients with AF and VTE, can be explained by underlying differences in the pathophysiology of these conditions and the synergistic effects achievable with DPI. Whereas higher doses of rivaroxaban are needed to target the fibrin-rich thrombi formed in AF and VTE, the rivaroxaban vascular dose as part of the dual inhibition strategy in combination with an antiplatelet agent is more likely to affect the formation of platelet-rich thrombi than anticoagulation alone in CVD. Because of the short half-life of $2.5 \mathrm{mg}$ doses, rivaroxaban needs to be administered twice daily in patients with CVD to ensure that a therapeutic effect is maintained throughout the day.

The benefit of DPI using the COMPASS regimen has been demonstrated in patients with a recent ACS, patients with chronic CAD or PAD, and in patients with lower extremity symptomatic PAD. ${ }^{25,29-32}$ So far, rivaroxaban is the only anticoagulant shown to be effective in combination with antiplatelet therapies in these settings.

Studies with other anticoagulants in combination with antiplatelet agents have not yet found a "sweet spot" where there is clinical benefit without an unacceptable risk of bleeding. Rivaroxaban and apixaban have divergent effects on the kinetics of prothrombinase inhibition and suppression of thrombin generation suggesting that dosing regimens will not be interchangeable. ${ }^{90}$ Without more data, therefore, rivaroxaban is currently the only oral factor Xa inhibitor that can be used as part of the DPI strategy.

Recent preclinical data reveal a potential role of factor Xa in PAR-mediated disease processes of the vessel wall and demonstrate potential benefits of factor Xa inhibition with rivaroxaban. ${ }^{91,92}$ The clinical relevance of these findings requires further investigation to broaden the indications for vascular protection with the DPI strategy.

\section{Note}

The authors were fully responsible for the content of the paper and made the decision to submit the manuscript. J.I.W. holds the Canada Research Chair in Thrombosis and the Heart and Stroke Foundation J. Fraser Mustard Chair in Cardiovascular Research.

\section{Funding}

Writing support was provided by Chameleon Communications International, Ltd, with funding from Bayer AG

\section{Conflict of Interest}

J.I.W. received honoraria from Anthos, Bayer AG, Boehringer Ingelheim, Bristol-Myers Squibb, Daiichi Sankyo, Ionis, Janssen, Novartis, Pfizer, PhaseBio, Portola, Servier, and
Tetherex Pharmaceuticals and institutional grants from Bayer AG and Boehringer Ingelheim. D.J.A. has received payment as an individual for: (a) consulting fee or honorarium from Amgen, Aralez Pharmaceuticals, AstraZeneca, Bayer AG, Biosensors, Boehringer Ingelheim, Bristol-Myers Squibb, Chiesi, Daiichi Sankyo, Eli Lilly, Haemonetics, Janssen, Merck, Pfizer, PhaseBio, PLx Pharma, Sanofi, and The Medicines Company; (b) participation in review activities from CeloNova BioSciences and St. Jude Medical; (c) institutional payments for grants from Amgen, AstraZeneca, Bayer AG, Biosensors, CeloNova BioSciences, CSL Behring, Daiichi Sankyo, Eisai, Eli Lilly, Gilead, Idorsia Pharmaceuticals, Janssen, Matsutani Chemical Industry Co., Merck, Novartis, Osprey Medical RenalGuard Solutions, and the Scott R. MacKenzie Foundation. T.G. received grants and personal fees from Bayer AG, Bristol-Myers Squibb, Daiichi Sankyo, and The Medicines Company, personal fees from AstraZeneca, Boehringer Ingelheim, Chiesi, Ferrer, MSD, and Pfizer, grants from Siemens Healthcare and Spartan Bioscience outside the submitted work. S.H. is an employee of Bayer AG. D.J.A. reports grants and personal fees from Amgen, grants and personal fees from Aralez, grants and personal fees from Bayer, grants and personal fees from Biosensors, grants and personal fees from Boehringer Ingelheim, grants and personal fees from Bristol-Myers Squibb, grants and personal fees from Chiesi, grants and personal fees from Daiichi-Sankyo, grants and personal fees from Eli Lilly, personal fees from Haemonetics, grants and personal fees from Janssen, grants and personal fees from Merck, personal fees from PhaseBio, personal fees from PLx Pharma, personal fees from Pfizer, grants and personal fees from Sanofi, personal fees from The Medicines company, grants and personal fees from CeloNova, personal fees from St Jude Medical, grants from CSL Behring, grants from Eisai, grants from Gilead, grants from Idorsia Pharmaceuticals Ltd, grants from Matsutani Chemical Industry Co., grants from Novartis, grants from Osprey Medical, grants from Renal Guard Solutions, grants from Scott R. MacKenzie Foundation, grants from NIH/NCATS Clinical and Translational Science Award to the University of Florida UL1 TR000064 and NIH/ NHGRI U01 HG007269, grants and personal fees from Astra Zeneca, outside the submitted work. T.G. reports personal fees from Astra Zeneca, personal fees from Boehringer Ingelheim, personal fees from Pfizer, grants and personal fees from Bayer AG, grants and personal fees from Bristol Myers Squibb, grants and personal fees from Daiichi Sankyo, grants and personal fees from Eli Lilly, personal fees from Ferrer, outside the submitted work. J.I.W. reports personal fees from Bayer, personal fees from Boehringer Ingelheim, personal fees from Bristol-Myers Squibb, personal fees from Daiichi-Sankyo, personal fees from Ionis, personal fees from Janssen, personal fees from Merck, personal fees from Novartis, personal fees from Pfizer, personal fees from Portola, outside the submitted work.

\section{References}

1 Drouet L. Atherothrombosis as a systemic disease. Cerebrovasc Dis 2002;13(Suppl 1):1-6 
2 Viles-Gonzalez JF, Fuster V, Badimon JJ. Atherothrombosis: a widespread disease with unpredictable and life-threatening consequences. Eur Heart J 2004;25(14):1197-1207

3 Badimon L, Padró T, Vilahur G. Atherosclerosis, platelets and thrombosis in acute ischaemic heart disease. Eur Heart J Acute Cardiovasc Care 2012;1(01):60-74

4 World Health Organization. The top 10 causes of death. 2018. Available at: http://www.who.int/mediacentre/factsheets/fs310/ en/. Accessed March 3, 2020

5 Falk E. Pathogenesis of atherosclerosis. J Am Coll Cardiol 2006;47 (08):C7-C12

6 World Health Organization. Cardiovascular diseases (CVDs). 2017. Available at: http://www.who.int/mediacentre/factsheets/fs317/en/. Accessed March 3, 2020

7 Joseph P, Leong D, McKee M, et al. Reducing the global burden of cardiovascular disease, part 1: the epidemiology and risk factors. Circ Res 2017;121(06):677-694

8 Bhatt DL, Steg PG, Ohman EM, et al; REACH Registry Investigators. International prevalence, recognition, and treatment of cardiovascular risk factors in outpatients with atherothrombosis. JAMA 2006;295(02):180-189

9 Steg PG, Bhatt DL, Wilson PW, et al; REACH Registry Investigators. One-year cardiovascular event rates in outpatients with atherothrombosis. JAMA 2007;297(11):1197-1206

10 Alberts MJ, Bhatt DL, Mas JL, et al; REduction of Atherothrombosis for Continued Health Registry Investigators. Three-year follow-up and event rates in the international REduction of Atherothrombosis for Continued Health Registry. Eur Heart J 2009;30(19): 2318-2326

11 Aboyans V, Ricco JB, Bartelink MEL, et al; ESC Scientific Document Group. 2017 ESC guidelines on the diagnosis and treatment of peripheral arterial diseases, in collaboration with the European Society for Vascular Surgery (ESVS): document covering atherosclerotic disease of extracranial carotid and vertebral, mesenteric, renal, upper and lower extremity arteries. Eur Heart J 2018;39 (09):763-816

12 Roffi M, Patrono C, Collet JP, et al; ESC Scientific Document Group. 2015 ESC guidelines for the management of acute coronary syndromes in patients presenting without persistent ST-segment elevation: Task Force for the Management of Acute Coronary Syndromes in Patients Presenting without Persistent ST-Segment Elevation of the European Society of Cardiology (ESC). Eur Heart J 2016;37(03):267-315

13 Ibanez B, James S, Agewall S, et al; ESC Scientific Document Group. 2017 ESC guidelines for the management of acute myocardial infarction in patients presenting with ST-segment elevation: the Task Force for the management of acute myocardial infarction in patients presenting with ST-segment elevation of the European Society of Cardiology (ESC). Eur Heart J 2018;39(02):119-177

14 Amsterdam EA, Wenger NK, Brindis RG, et al. 2014 AHA/ACC guideline for the management of patients with non-ST-elevation acute coronary syndromes: a report of the American College of Cardiology/American Heart Association task force on practice guidelines. J Am Coll Cardiol 2014;64(24):e139-e228

15 O'Gara PT, Kushner FG, Ascheim DD, et al; American College of Cardiology Foundation/American Heart Association Task Force on Practice Guidelines. 2013 ACCF/AHA guideline for the management of ST-elevation myocardial infarction: a report of the American College of Cardiology Foundation/American Heart Association task force on practice guidelines. Circulation 2013;127 (04):e362-e425

16 Montalescot G, Sechtem U, Achenbach S, et al; Task Force Members; ESC Committee for Practice Guidelines; Document Reviewers. 2013 ESC guidelines on the management of stable coronary artery disease: the Task Force on the management of stable coronary artery disease of the European Society of Cardiology. Eur Heart J 2013;34(38):2949-3003
17 Weitz JI. Insights into the role of thrombin in the pathogenesis of recurrent ischaemia after acute coronary syndrome. Thromb Haemost 2014;112(05):924-931

18 Capodanno D, Alfonso F, Levine GN, Valgimigli M, Angiolillo DJ. ACC/AHA versus ESC guidelines on dual antiplatelet therapy: JACC guideline comparison. J Am Coll Cardiol 2018;72(23 Pt A):2915-2931

19 Gerhard-Herman MD, Gornik HL, Barrett C, et al. 2016 AHA/ACC guideline on the management of patients with lower extremity peripheral artery disease: a report of the American College of Cardiology/American Heart Association task force on clinical practice guidelines. Circulation 2017;135(12):e726-e779

20 Knuuti J, Wijns W, Saraste A, et al; ESC Scientific Document Group. 2019 ESC guidelines for the diagnosis and management of chronic coronary syndromes. Eur Heart J 2020;41(03):407-477

21 O'Donoghue ML, Braunwald E, White HD, et al; SOLID-TIMI 52 Investigators. Effect of darapladib on major coronary events after an acute coronary syndrome: the SOLID-TIMI 52 randomized clinical trial. JAMA 2014;312(10):1006-1015

22 Rapsomaniki E, Thuresson M, Yang E, et al. Using big data from health records from four countries to evaluate chronic disease outcomes: a study in 114364 survivors of myocardial infarction. Eur Heart J Qual Care Clin Outcomes 2016;2(03):172-183

23 Falk E, Nakano M, Bentzon JF, Finn AV, Virmani R. Update on acute coronary syndromes: the pathologists' view. Eur Heart J 2013;34 (10):719-728

24 Badimon L, Vilahur G. Thrombosis formation on atherosclerotic lesions and plaque rupture. J Intern Med 2014;276(06):618-632

25 Mega JL, Braunwald E, Wiviott SD, et al; ATLAS ACS 2-TIMI 51 Investigators. Rivaroxaban in patients with a recent acute coronary syndrome. N Engl J Med 2012;366(01):9-19

26 Janssen Pharmaceuticals Inc. Xarelto ${ }^{\circledR}$ (rivaroxaban) Prescribing Information. 2019. Available at: http://www.janssenlabels.com/package-insert/product-monograph/prescribing-information/XARELTO-pi.pdf. Accessed December 24, 2019

27 Bayer AG. Xarelto ${ }^{\circledR}$ (rivaroxaban) Summary of Product Characteristics. Available at: https://www.ema.europa.eu/documents/product-information/xarelto-epar-product-information_en.pdf. Accessed April 9, 2020

28 Bayer Inc. Xarelto ${ }^{\circledR}$ (rivaroxaban tablets) Product Monograph. 2019. Available at: http://omr.bayer.ca/omr/online/xarelto-pmen.pdf. Accessed February 10, 2020

29 Eikelboom JW, Connolly SJ, Bosch J, et al; COMPASS Investigators. Rivaroxaban with or without aspirin in stable cardiovascular disease. N Engl J Med 2017;377(14):1319-1330

30 Connolly SJ, Eikelboom JW, Bosch J, et al; COMPASS investigators. Rivaroxaban with or without aspirin in patients with stable coronary artery disease: an international, randomised, doubleblind, placebo-controlled trial. Lancet 2018;391(10117):205-218

31 Anand SS, Bosch J, Eikelboom JW, et al; COMPASS Investigators. Rivaroxaban with or without aspirin in patients with stable peripheral or carotid artery disease: an international, randomised, double-blind, placebo-controlled trial. Lancet 2018;391 (10117):219-229

32 Bonaca MP, Bauersachs RM, Anand SS, et al. Rivaroxaban in peripheral artery disease after revascularization. $\mathrm{N}$ Engl J Med 2020;382(21):1994-2004

33 Sharma M, Hart RG, Connolly SJ, et al. Stroke outcomes in the Cardiovascular OutcoMes for People using Anticoagulation StrategieS (COMPASS) trial. Circulation 2019;139:1134-1145

34 Perera KS, Ng KKH, Nayar S, et al. Association between low-dose rivaroxaban with or without aspirin and ischemic stroke subtypes: a secondary analysis of the COMPASS trial. JAMA Neurol 2019;77(01):43-48

35 Stefanadis C, Antoniou CK, Tsiachris D, Pietri P. Coronary atherosclerotic vulnerable plaque: current perspectives. J Am Heart Assoc 2017;6(03):e005543 
36 Weitz JI, Eikelboom JW. Advances in thrombosis and hemostasis: an introduction to the compendium. Circ Res 2016;118(09): 1337-1339

37 White H. Targeting therapy to the fibrin-mediated pathophysiology of acute coronary syndrome. Clin Appl Thromb Hemost 2014; 20(05):516-523

38 Olie RH, van der Meijden PEJ, Ten Cate H. The coagulation system in atherothrombosis: implications for new therapeutic strategies. Res Pract Thromb Haemost 2018;2(02):188-198

39 Petzold T, Thienel M, Dannenberg L, et al. Rivaroxaban reduces arterial thrombosis by inhibition of FXa-driven platelet activation via protease activated receptor-1. Circ Res 2020;126(04):486-500

40 Martínez-Sales V, Vila V, Réganon E, et al. Elevated thrombotic activity after myocardial infarction: a 2-year follow-up study. Haemostasis 1998;28(06):301-306

41 Smid M, Dielis AW, Spronk HM, et al. Thrombin generation in the Glasgow Myocardial Infarction Study. PLoS One 2013;8(06): e66977

42 AlKhalfan F, Kerneis M, Nafee T, et al. D-dimer levels and effect of rivaroxaban on those levels and outcomes in patients with acute coronary syndrome (an ATLAS ACS-TIMI 46 trial substudy). Am J Cardiol 2018;122(09):1459-1464

43 Perzborn E, Heitmeier S, Laux V. Effects of rivaroxaban on platelet activation and platelet-coagulation pathway interaction: in vitro and in vivo studies. J Cardiovasc Pharmacol Ther 2015;20(06):554-562

44 Becker EM, Perzborn E, Klipp A, et al. Effects of rivaroxaban, acetylsalicylic acid and clopidogrel as monotherapy and in combination in a porcine model of stent thrombosis. J Thromb Haemost 2012;10(12):2470-2480

45 Borst $\mathrm{O}$, Münzer $\mathrm{P}$, Alnaggar N, et al. Inhibitory mechanisms of very low-dose rivaroxaban in non-ST-elevation myocardial infarction. Blood Adv 2018;2(06):715-730

46 Bhatt DL, Fox KAA, Hacke W, et al; CHARISMA Investigators. Clopidogrel and aspirin versus aspirin alone for the prevention of atherothrombotic events. N Engl J Med 2006;354(16): 1706-1717

47 Bhatt DL, Flather MD, Hacke W, et al; CHARISMA Investigators. Patients with prior myocardial infarction, stroke, or symptomatic peripheral arterial disease in the CHARISMA trial. J Am Coll Cardiol 2007;49(19):1982-1988

48 Bonaca MP, Bhatt DL, Storey RF, et al. Ticagrelor for prevention of ischemic events after myocardial infarction in patients with peripheral artery disease. J Am Coll Cardiol 2016;67(23): 2719-2728

49 Bonaca MP, Bhatt DL, Cohen M, et al; PEGASUS-TIMI 54 Steering Committee and Investigators. Long-term use of ticagrelor in patients with prior myocardial infarction. N Engl J Med 2015; 372(19):1791-1800

50 Hiatt WR, Fowkes FG, Heizer G, et al; EUCLID Trial Steering Committee and Investigators. Ticagrelor versus clopidogrel in symptomatic peripheral artery disease. N Engl J Med 2017;376 (01):32-40

51 Morrow DA, Braunwald E, Bonaca MP, et al; TRA 2P-TIMI 50 Steering Committee and Investigators. Vorapaxar in the secondary prevention of atherothrombotic events. N Engl J Med 2012; 366(15):1404-1413

52 Scirica BM, Bonaca MP, Braunwald E, et al; TRA $2^{\circ} \mathrm{P}-\mathrm{TIMI} 50$ Steering Committee Investigators. Vorapaxar for secondary prevention of thrombotic events for patients with previous myocardial infarction: a prespecified subgroup analysis of the TRA $2^{\circ} \mathrm{P}$ TIMI 50 trial. Lancet 2012;380(9850):1317-1324

53 Tricoci P, Huang Z, Held C, et al; TRACER Investigators. Thrombinreceptor antagonist vorapaxar in acute coronary syndromes. $\mathrm{N}$ Engl J Med 2012;366(01):20-33

54 van Es RF, Jonker JJ, Verheugt FW, Deckers JW, Grobbee DE; Antithrombotics in the Secondary Prevention of Events in Coronary Thrombosis-2 (ASPECT-2) Research Group. Aspirin and coumadin after acute coronary syndromes (the ASPECT-2 study): a randomised controlled trial. Lancet 2002;360(9327):109-113

55 Hurlen M, Abdelnoor M, Smith P, Erikssen J, Arnesen H. Warfarin, aspirin, or both after myocardial infarction. N Engl J Med 2002; 347(13):969-974

56 Fiore LD, Ezekowitz MD, Brophy MT, Lu D, Sacco J, Peduzzi P; Combination Hemotherapy and Mortality Prevention (CHAMP) Study Group. Department of Veterans Affairs Cooperative Studies Program Clinical Trial comparing combined warfarin and aspirin with aspirin alone in survivors of acute myocardial infarction: primary results of the CHAMP study. Circulation 2002;105(05): 557-563

57 Sun Pharmaceutical Industries Europe BV. Coumadin (Warfarin $0.5 \mathrm{mg}$ ) Summary of Product Characteristics. 2017. Available at: http://www.medicines.org.uk/emc/medicine/27651. Accessed September 23, 2019

58 Bristol-Myers Squibb Company. Coumadin (warfarin sodium) Prescribing Information. 2019. Available at: http://packageinserts.bms.com/pi/pi_coumadin.pdf. Accessed March 9, 2020

59 Wolzt M, Gouya G, Kapiotis S, Becka M, Mueck W, Kubitza D. Open-label, randomized study of the effect of rivaroxaban with or without acetylsalicylic acid on thrombus formation in a perfusion chamber. Thromb Res 2013;132(02):240-247

60 Weisshaar S, Litschauer B, Bucher S, et al. The effect of a dual or a triple antithrombotic therapy with apixaban on thrombus formation in vivo and in an ex vivo perfusion chamber model: an open-label, controlled, sequential study. Medicine (Baltimore) 2016;95(27):e4145

61 Honda Y, Kamisato C, Morishima Y. Edoxaban, a direct factor Xa inhibitor, suppresses tissue-factor induced human platelet aggregation and clot-bound factor $\mathrm{Xa}$ in vitro: Comparison with an antithrombin-dependent factor $\mathrm{Xa}$ inhibitor, fondaparinux. Thromb Res 2016;141:17-21

62 Daiichi Sankyo Europe Gmb H. Lixiana ${ }^{\circledR}$ (edoxaban) Summary of Product Characteristics. Available at: http://www.ema.europa. eu/docs/en_GB/document_library/EPAR_-_Product_Information/ human/002629/WC500189045.pdf. Accessed April 9, 2020

63 Boehringer Ingelheim International GmbH. Jardiance ${ }^{\circledR}$ (empagliflozin) Summary of Product Characteristics. 2019. Available at: https://www.ema.europa.eu/documents/product-information/jardiance-epar-product-information_en.pdf. Accessed November 27, 2019

64 Ruff CT, Giugliano RP, Braunwald E, et al. Comparison of the efficacy and safety of new oral anticoagulants with warfarin in patients with atrial fibrillation: a meta-analysis of randomised trials. Lancet 2014;383(9921):955-962

65 van der Hulle T, Kooiman J, den Exter PL, Dekkers OM, Klok FA, Huisman MV. Effectiveness and safety of novel oral anticoagulants as compared with vitamin $\mathrm{K}$ antagonists in the treatment of acute symptomatic venous thromboembolism: a systematic review and meta-analysis. J Thromb Haemost 2014;12(03):320-328

66 Alexander JH, Lopes RD, James S, et al; APPRAISE-2 Investigators. Apixaban with antiplatelet therapy after acute coronary syndrome. N Engl J Med 2011;365(08):699-708

67 Oldgren J, Budaj A, Granger CB, et al; RE-DEEM Investigators. Dabigatran vs. placebo in patients with acute coronary syndromes on dual antiplatelet therapy: a randomized, double-blind, phase II trial. Eur Heart J 2011;32(22):2781-2789

68 Granger CB, Alexander JH, McMurray JJ, et al; ARISTOTLE Committees and Investigators. Apixaban versus warfarin in patients with atrial fibrillation. N Engl J Med 2011;365(11):981-992

69 Mega JL, Braunwald E, Mohanavelu S, et al; ATLAS ACS-TIMI 46 study group. Rivaroxaban versus placebo in patients with acute coronary syndromes (ATLAS ACS-TIMI 46): a randomised, doubleblind, phase II trial. Lancet 2009;374(9683):29-38

70 Gibson CM, Chakrabarti AK, Mega J, et al; ATLAS-ACS 2 TIMI 51 Investigators. Reduction of stent thrombosis in patients with 
acute coronary syndromes treated with rivaroxaban in ATLASACS 2 TIMI 51. J Am Coll Cardiol 2013;62(04):286-290

71 Ohman EM, Roe MT, Steg PG, et al. Clinically significant bleeding with low-dose rivaroxaban versus aspirin, in addition to P2Y12 inhibition, in acute coronary syndromes (GEMINI-ACS-1): a double-blind, multicentre, randomised trial. Lancet 2017;389 (10081):1799-1808

72 Patel MR, Mahaffey KW, Garg J, et al; ROCKET AF Investigators. Rivaroxaban versus warfarin in nonvalvular atrial fibrillation. N Engl J Med 2011;365(10):883-891

73 Kirchhof P, Benussi S, Kotecha D, et al. 2016 ESC guidelines for the management of atrial fibrillation developed in collaboration with EACTS. Europace 2016;18(11):1609-1678

74 Casa LD, Deaton DH, Ku DN. Role of high shear rate in thrombosis. J Vasc Surg 2015;61(04):1068-1080

75 Kubitza D, Becka M, Wensing G, Voith B, Zuehlsdorf M. Safety, pharmacodynamics, and pharmacokinetics of BAY 59-7939-an oral, direct Factor Xa inhibitor-after multiple dosing in healthy male subjects. Eur J Clin Pharmacol 2005;61(12):873-880

76 Kubitza D, Berkowitz SD, Misselwitz F. Evidence-based development and rationale for once-daily rivaroxaban dosing regimens across multiple indications. Clin Appl Thromb Hemost 2016;22(05):412-422

77 Kreutz R. Pharmacokinetics and pharmacodynamics of rivaroxaban-an oral, direct factor Xa inhibitor. Curr Clin Pharmacol 2014;9(01):75-83

78 Kubitza D, Becka M, Voith B, Zuehlsdorf M, Wensing G. Safety, pharmacodynamics, and pharmacokinetics of single doses of BAY 59-7939, an oral, direct factor Xa inhibitor. Clin Pharmacol Ther 2005;78(04):412-421

79 Stampfuss J, Kubitza D, Becka M, Mueck W. The effect of food on the absorption and pharmacokinetics of rivaroxaban. Int J Clin Pharmacol Ther 2013;51(07):549-561

80 Agnelli G, Gallus A, Goldhaber SZ, et al; ODIXa-DVT Study Investigators. Treatment of proximal deep-vein thrombosis with the oral direct factor Xa inhibitor rivaroxaban (BAY 59-7939): the ODIXa-DVT (Oral Direct Factor Xa Inhibitor BAY 59-7939 in Patients With Acute Symptomatic Deep-Vein Thrombosis) study. Circulation 2007;116(02):180-187

81 Buller HR, Lensing AWA, Prins MH, et al; Einstein-DVT DoseRanging Study investigators. A dose-ranging study evaluating once-daily oral administration of the factor Xa inhibitor rivaroxaban in the treatment of patients with acute symptomatic deep vein thrombosis: the Einstein-DVT Dose-Ranging Study. Blood 2008;112(06):2242-2247
82 ROCKET AF Study Investigators. Rivaroxaban-once daily, oral, direct factor Xa inhibition compared with vitamin $\mathrm{K}$ antagonism for prevention of stroke and Embolism Trial in Atrial Fibrillation: rationale and design of the ROCKET AF study. Am Heart J 2010;159 (03):340-347

83 Anand SS, Eikelboom JW, Dyal L, et al; COMPASS Trial Investigators. Rivaroxaban plus aspirin versus aspirin in relation to vascular risk in the COMPASS trial. J Am Coll Cardiol 2019;73 (25):3271-3280

84 Capodanno D, Bhatt DL, Eikelboom JW, et al. Dual-pathway inhibition for secondary and tertiary antithrombotic prevention in cardiovascular disease. Nat Rev Cardiol 2020;17(04):242-257

85 Darmon A, Sorbets E, Ducrocq G, et al; REACH Registry Investigators. Association of multiple enrichment criteria with ischemic and bleeding risks among COMPASS-eligible patients. J Am Coll Cardiol 2019;73(25):3281-3291

86 Fox KAA, Eikelboom JW, Anand SS, et al. Anti-thrombotic options for secondary prevention in patients with chronic atherosclerotic vascular disease: what does COMPASS add? Eur Heart J 2019;40 (18):1466-1471

87 Sumaya W, Geisler T, Kristensen SD, Storey RF. Dual antiplatelet or dual antithrombotic therapy for secondary prevention in high-risk patients with stable coronary artery disease? Thromb Haemost 2019;19(10):1583-1589

88 de Vries TI, Eikelboom JW, Bosch J, et al. Estimating individual lifetime benefit and bleeding risk of adding rivaroxaban to aspirin for patients with stable cardiovascular disease: results from the COMPASS trial. Eur Heart J 2019;40(46):3771-3778

89 Hussain MA, Al-Omran M, Creager MA, Anand SS, Verma S, Bhatt DL. Antithrombotic therapy for peripheral artery disease: recent advances. J Am Coll Cardiol 2018;71(21):2450-2467

$90 \mathrm{Kim}$ PY, Yeh CH, Dale BJ, et al. Mechanistic basis for the differential effects of rivaroxaban and apixaban on global tests of coagulation. TH Open 2018;2(02):e190-e201

91 Ellinghaus P, Perzborn E, Hauenschild P, et al. Expression of proinflammatory genes in human endothelial cells: Comparison of rivaroxaban and dabigatran. Thromb Res 2016;142:44-51

92 Álvarez E, Paradela-Dobarro B, Raposeiras-Roubín S, González-Juanatey JR. Protective, repairing and fibrinolytic effects of rivaroxaban on vascular endothelium. Br J Clin Pharmacol 2018;84(02):280-291

93 Capell WH, Bonaca MP, Nehler MR, et al. Rationale and design for the Vascular Outcomes study of ASA along with rivaroxaban in endovascular or surgical limb revascularization for peripheral artery disease (VOYAGER PAD). Am Heart J 2018;199:83-91 